\title{
Le spectacle de la culture. Globalisation et traditionalismes en Océanie d'Alain Babadzan
}

\section{Raymond MAYER}

\section{OpenEdition}

1 Journals

\section{Édition électronique}

URL : http://journals.openedition.org/jso/6163

DOI : $10.4000 /$ jso.6163

ISSN : $1760-7256$

\section{Éditeur}

Société des océanistes

\section{Édition imprimée}

Date de publication : 15 décembre 2010

Pagination : 253-255

ISBN : 978-2-85430-027-7

ISSN : 0300-953x

Référence électronique

Raymond MAYER, « Le spectacle de la culture. Globalisation et traditionalismes en Océanie d'Alain Babadzan », Journal de la Société des Océanistes [En ligne], 130-131 | 2010, mis en ligne le 15 décembre 2010, consulté le 23 septembre 2020. URL : http://journals.openedition.org/jso/6163 ; DOI : https:// doi.org/10.4000/jso.6163 
étrangers sur un pied d'égalité. Il relève en passant la création de plusieurs départements d'anthropologie dans diverses universités de son pays.

L'ancienne conservatrice du musée d'Israël de Jérusalem, Aviva Muller-Lancet, part du principe d'une " société composite" dans son pays fondée sur au moins quatre mouvances inaliénables (pp. 133-143) : arabes-et-non-juives, juives ultra-orthodoxes, juives modernes et juives pionnières. Même si c'est la diversité des cultures juives de la diaspora qui a surtout retenu l'attention de son travail muséographique et ethnographique, sa contribution permet de voir un peu plus clair dans l'écheveau des tendances qui traversent quotidiennement la vie politique et sociale de son pays.

Edit Fèl, ancienne professeur à l'université de Budapest, fait constater qu'en Europe centrale, se sont développées des ethnologies nationales en marge des courants universalistes incarnés par les grandes écoles britanniques, américaines, allemandes et françaises (pp. 145-156). Le résultat de cet intérêt manifesté pour les objets et des mentalités qui leur donnent vie (on appréciera les exemples qualitatifs du traitement de la houe, diversifiée suivant les âges et les personnes, ainsi que de la grange à réunion des hommes en marge des villages) est certes celui d'un outil intellectuel au service d'une cause nationaliste, mais aussi la richesse d'une recherche autonome qui ne s'embarrasse pas des querelles d'école étrangères pour constituer un fonds documentaire inégalé et inégalable.

Comment une ancienne archéologue se reconvertit aux vertus de l'ethnographie du contemporain dans un milieu dont elle parle la langue (« celle qui implique un rapport d'égal à égal », p. 167), mais dont les tensions internes ne peuvent manquer de rejaillir sur le travail de l'anthropologue, telle est la belle et tonique réflexion d'Yvonne de Sike sur une île de la mer Egée. Dans le cas particulier des îles grecques (mais le cas est-il si particulier?), les insulaires se méfient des « sociologues » (p. 165) et de tous ceux qui s'intéressent de trop près aux dessous des problèmes quotidiens. Le charisme personnel de l'anthropologue le (ou la) rend seul(e) capable de travailler dans un climat de confiance/méfiance permanent.

Encore plus solennel et plus cérémonieux : c'est un véritable tribunal qui accueillit l'anthropologue Joaquin Galarza (pp. 169-181), déchiffreur de codex du $\mathrm{XVII}^{\mathrm{e}}$ siècle, dans un village au sud du Mexique qui en détenait des exemplaires inédits. La condition d'admission dans ce cercle masculin ultra-fermé était de démontrer sa compétence au service des intérêts locaux, et d'apporter, en une sorte de contre-don préalable, des éléments matériels d'égale valeur (ici des photographies de documents anciens) : la preuve par une mise à l'épreuve initiale ! C'est un cas très précis qui devrait faire école - d'un examen de passage préalable à l'accès au terrain.

Jean Guiart a donc fait appel à des auteurs confirmés, dont une riche bibliographie accompagne généralement le témoignage, ce qui donne un panorama diversifié de la situation mondiale, présenté autrement qu'à partir des métropoles dominantes. On retiendra surtout que, contrairement aux effets attendus de la mondialisation claironnés sur tous les tons, l'échelle nationale est déterminante pour saisir l'environnement scientifique postcolonial des recherches menées sur le terrain. Les conditions d'accès au terrain ne sont donc qu'un indicateur parmi d'autres de la nouvelle donne de l'anthropologie mondiale. Le filtre universitaire de chaque État souverain définit à présent les objectifs prioritaires de toute recherche, indépendamment des tendances d'école autrefois régentées par les seules anthropologies " hégémoniques ». Le renversement des priorités, un peu du jour au lendemain, au sortir d'âpres luttes anticoloniales, est un des signes les plus manifestes de la différence réelle entre exo- et endo-anthropologies, le nouveau système de légitimation mettant à nu le précédent qui opérait jusque-là à son insu.

Au terme de cette revue de tour de monde anthropologique, on retire l'impression de capacités nationales qui ne demandent qu'à éclore et à fructifier. On sent surtout une complémentarité forte entre les divers témoignages rassemblés. Mais forcer à la reconnaissance et au respect de cette diversité d'expression qui indéniablement commence à semer à tous vents sur le plan mondial, est justement l'objectif de cette publication indispensable. L'essentiel a été montré : le vin est tiré, il faut le boire.

\section{RÉFÉRENCES CITÉES}

BERnAUlt Florence, 2001. L'Afrique et la modernité des sciences sociales, Le vingtième siècle. Revue d'histoire 70, pp. 127-138.

FogEL Frédérique, 2006. Le mariage dit arabe, L'Homme 177-178, pp. 373-394.

Raymond MAYER, Université Omar Bongo de Libreville et Université de Lyon 2

Babadzan Alain, 2009. Le spectacle de la culture. Globalisation et traditionalismes en Océanie, Paris, L'Harmattan, coll. Connaissance des hommes, bibliogr., $286 \mathrm{p}$.

Alain Babadzan a eu raison de colliger en un volume récapitulatif les fines analyses réalisées à chaud, pendant trente ans, sur la singulière idéologie politique océanienne mise en scène dans les anciens, nouveaux et futurs États de cette région du monde en devenir. La manière inédite de placer les indépendances sous le signe de la culture (et de ses alternymes « coutume » et « tradition ») aurait pu réjouir les anthropologues des cinq continents. Pour la première fois, ils tenaient là un modèle vivant qui hypostasiait un de leurs concepts de base, aussi sûrement qu'on avait placé la déesse Raison sur les autels de la Révolution française ! Mais, et c'est évidement tout l'intérêt du livre, Alain Babadzan a beau jeu de montrer et démontrer que la réalité est bien plus complexe et plus ambiguë, et que le résultat est promis à des révisions certaines. Sur ce point, le livre 
réalise non seulement, comme on peut s'y attendre, une synthèse des courants de pensée politique qui régissent le postcolonialisme en Océanie, mais il en restitue les aspects processuels, ce qui double largement son utilité permanente.

Dans son offre de lecture et d'analyse, Alain Babadzan place son ouvrage sous le signe de l'évolution du couple "globalisation et traditionalismes » dans le contexte spécifique de l'Océanie. À moins de considérer la période de « l'authenticité zaïroise » du régime Mobutu comme une variante africaine de l'Étatculture, et à moins de falsifier « la révolution culturelle » du régime maoïste en variante asiatique d'un travestissement culturel de la répression, on a tout lieu de croire que la culture comme religion d'État représente en effet un isolat idéologique océanien et que l'on a affaire à un phénomène insolite qui serait circonscrit (pour une fois ?) dans l'espace et dans le temps. Sur l'échiquier mondial, le fait d'ériger la culture en doctrine d'État apparaît comme un hapax de l'Océanie du Sud (tant il est vrai que l'État de Hawaii y échappe, mais non pas les «American Samoa» par exemple). On pourrait remarquer d'ailleurs que ce " concept » transcende le phénomène des indépendances, puisqu'on peut considérer que la « coutume » de Nouvelle-Calédonie (Monnerie, 2005) et les « rois » de Wallis-et-Futuna (Favole, 2000), sans doute moins les «juillet » de la Polynésie française, relèvent de la même mouvance idéologique. En tout cas, grâce à Alain Babadzan et aux nombreux auteurs cités en cours d'analyse, on n'aura pas attendu les calendes grecques pour en saisir le surgissement, et le livre nous offre une première synthèse que l'on prendra plaisir à vérifier dans le demi-siècle que nous entamons. Car c'est en même temps un livre à thèse, qui annonce la fin des Trente Glorieuses de la culture dans le Pacifique et qui stipule que c'en est fini de la « coutume » comme référent constitutionnel, puisque l'auteur y prédit la dépolitisation de la culture, remplacée à terme par les lois du marché international, y compris du marché politique.

Dans sa démonstration, ce livre-recueil est articulé en sept chapitres qui nous installent de plain-pied dans la problématique, en variant les sites et les thèmes, mais en conservant l'unité d'intérêt. Le premier chapitre (pp. 15-73) nous plonge dans l'État de coutume, sous son appellation-pidgin de kastom (de l'anglais standard custom, lui-même probablement de l'ancien français : coutume). Il retrace l'émergence d'un autre concept en honneur depuis les années 1970, celui de "Pacific Way». Celui-ci servait à la fois de concept englobant et de slogan idéologique commun à tous les micro-États naissants. La création des festivals du Pacifique est interprétée comme le passage du rite au spectacle, ce qui corrobore l'idée dominante du livre, lui donne son idée roborative et justifie son titre (Baré, 2010). L'exemple emblématique des Gogodala du golfe de Papouasie ayant brûlé tous leurs objets rituels après le passage des évangélistes et qui finirent par danser devant Elizabeth II à l'occasion de son jubilé, récapitule en quelques traits et autant de tableaux, l'aventure et les péripéties des peuples et cultures jetés en pâture à la fois aux traditionnalismes et à la globa- lisation, passant « du rite au spectacle, et du folklore à la marchandisation de la culture » (p. 67). Mais l'analyse d'Alain Babadzan, si elle met du miel aux cendres, sait justement lire les lames de fond qui parcourent un océan de dynamiques complexes qui ne sauraient à aucun moment être réduites à une seule. Le livre se lit comme une success story, à l'image des « renaissances » culturelles dont il fait précisément état. Il n'y a que la fin qui soit résolument pessimiste, puisque l'auteur se résout à n'en voir d'autre que celle de la disparition de cette heureuse (?) période pan-culturelle.

Le chapitre 2 (pp. 75-124) nous fait participer à un atelier sur la déconstruction du concept de «tradition », soumis à « l'offensive postmoderniste » selon l'expression de l'auteur. Par rapport au chapitre précédent, l'idée qu'il soutient est en effet que le désenchantement a également gagné le cœur du Pacifique, que les "grands récits » ont perdu de leur unanimisme, et que par conséquent, il convient de nuancer les aspects du concept au fur et à mesure de sa critique à la fois populaire et scientifique.

Le chapitre 3 (pp. 125-168) part des théories couramment diffusées par ou à propos de Hobsbawm et Gellner sur « l'invention de la tradition » pour situer le rapport à la culture dans un contexte de nationalisme et de modernisation politique. Indépendamment de la bonne compréhension des théories qui servent de référent commun - «A-t-on lu Hobsbawm ?»-, l'auteur examine les ruptures et continuités dans le sens de la constitution de nouvelles élites et de « nouveaux clercs » des jeunes États en voie d'émancipation.

Le chapitre 4 (pp. 169-192) revient sur le concept de « permanence culturelle » chez Marshall Sahlins pour montrer les limites de l' « indigénisation de la modernité » dans les États nouvellement constitués. Il prend comme terrain d'application le «culture movement » qui a marqué la période des indépendances.

Le chapitre 5 (pp. 193-210) s'attache à un autre concept rayonnant de l'anthropologie $\mathrm{du} \mathrm{xx}^{\mathrm{e}}$ siècle, celui de « syncrétisme ». Loin d'en faire un concept clé de l'adaptation sociale et religieuse, Alain Babadzan y dénote une "double négation": une négation des racines et une négation de la modernité. Il montre qu'il s'agit d'une sorte de concept aveugle, et non du concept rayonnant que les sciences sociales ont cru pouvoir détenir pour définir la période des grandes mutations dans les pays tiers.

Le chapitre 6 (pp. 211-250) traite de l'exemple particulier, mais évidemment largement suggestif d'une tendance générale, celui de la "renaissance maorie » qui aboutit de fait à la réalisation d'un « capitalisme néotribal », selon les termes de l'auteur. Le passage du niveau culturel au niveau économique et financier atteste de l'emprise progressive de ce dernier, et en même inaugure le déclin de la "culture » au profit d'autres valeurs qui lui échappent, et qui confinent en définitive à sa négation. L'histoire récente mise en lien avec l'histoire ancienne traduit un mouvement de « retribalisation» illustrée par les actions menées autour du tribunal de Waitangi, entendons par là la remise en honneur de l'appropriation des droits fonciers coutumiers. 
Enfin, dernier mais non moins des moindres, le chapitre 7 (pp. 251-266) se livre à une prospective sans ambages s'appuyant sur l'évolution des rapports entre les États "protecteurs» des indépendances océaniennes et leur cours précédent. L'auteur soutient la thèse du « crépuscule de la coutume », en le rapportant au «tournant néolibéral » qui marque les politiques des puissances mondiales dans la première décennie du XXI ${ }^{\mathrm{e}}$ siècle. Moment de l'histoire, mais surtout moment de l'histoire des idées, et, pour rester dans la métaphore de l'auteur, nouveau scénario politique fondé sur une «guerre contre la coutume? " Il est intéressant de voir comment les luttes anti-terrorisme procèdent par amalgame pour accréditer l'idée que ce qui était bon la veille est devenu mauvais le lendemain.

Au fil des articles qui ont constitué autant de chapitres du livre, Alain Babadzan nous a ainsi fait passer de la naissance à l'affaissement d'un grand concept englobant qui aura donné aux États océaniens leur première figure symbolique majeure. Il nous fait vivre, le temps d'un livre, les raisons qui ont poussé à l'émergence symbolique d'un concept global, et les mêmes raisons qui ont entraîné son déclin. Sur la question politique de l'Océanie et, par comparaison (Amselle, 2010), de nombreuses autres entités géopolitiques, on tient là assurément un ouvrage de base.

\section{RÉFÉRENCES CITÉES}

Amselle Jean-Loup, 2010. Le retour de l'indigène, L'Homme 194, pp. 131-138.

BARRÉ Jean-François, 2010. L'identité au miroir de Tahiti, L'Homme 194, pp. 139-155.

Favole Adriano, 2000. La palma del potere, Torino, il Segnalibro, $348 \mathrm{p}$.

Monnerie Denis, 2005. La parole de notre maison. Discours et cérémonies kanak aujourd'hui (NouvelleCalédonie), Paris, CNRs Éditions - Éditions de la maison des sciences de l'homme, $287 \mathrm{p}$.

Raymond MAYER, Université Omar Bongo de Libreville et Université de Lyon 2

GAGNÉ Natacha et Laurent JÉRôME (éds), 2009. Jeunesses autochtones. Affirmation, innovation et résistance dans les mondes contemporains, Rennes, Presses universitaires de Rennes (PUR), 195 p., bibliogr. après chaque contribution.

Cet ouvrage collectif ${ }^{23}$ rassemble sept contributions (dont trois sur l'Océanie) précédées d'une préface de Mona Belleau, jeune Inuk d'Iqaluit au Nunavut (pp. 9-12), d'une présentation des deux éditeurs scientifiques (pp. 13-20) et d'une introduction de Sylvie Poirier, spécialiste des Aborigènes d'Australie, sur
«Les dynamiques relationnelles des jeunes autochtones » (pp. 21-36). Quelques mots sur les auteurs terminent l'ouvrage (pp. 191-193).

Comme le présentent Natacha Gagné et Laurent Jérôme, ce recueil, " en ouvrant la question de la jeunesse autochtone à de nouvelles perspectives analytiques et à de nouveaux terrains ethnographiques ", veut explorer « les différentes stratégies déployées par les jeunes autochtones pour donner sens aux mondes auxquels ils participent activement » (p. 14).

En s'interrogeant sur ce qu'est d'être jeune et autochtone dans un monde globalisé, les contributions passent en revue diverses situations. Comme le signale d'emblée Sylvie Poirier, il faut d'abord savoir ce que représente la «catégorie sociale» de la «jeunesse », située " entre l'enfance et l'âge adulte », qui « est apparue assez récemment dans les sociétés occidentales modernes (au XIX ${ }^{\mathrm{e}}$ siècle) et avec elle, ce que l'on appelle depuis le début du $\mathrm{xx}^{\mathrm{e}}$ siècle, le fossé des générations » (p. 21). Ensuite, on peut donc se demander ce qu'est la catégorie sociale de « jeunes autochtones », en insistant sur le fait que « dans la majorité des sociétés autochtones, [...] la "jeunesse" est [...] devenue une catégorie sociale à partir du moment où ont cessé les rites initiatiques, ceux-là même qui consacraient le passage de l'enfance à l'âge adulte » (p. 22), tout en rappelant qu'il faut « user de prudence dans l'usage de la catégorie sociales des "jeunes" et de son application aux contextes autochtones » (p. 23). C'est notamment au travers des relations intergénérationnelles dans chaque société autochtone concernée que l'on peut la définir, en précisant « le sens de la communauté, le sens d'appartenance, de solidarité et de responsabilité face à la famille élargie » (p. 23) sans oublier l'importance de la parenté :

«On ne doit pas négliger le fait que dans les communautés autochtones, en règle générale, les relations et réseaux de parenté, et ce qu'ils impliquent, représentent encore les principaux vecteurs identitaires. » (p. 24)

Ainsi, dans de nombreuses sociétés, notamment celles ayant subi les « souffrance et [...] ruptures de la période coloniale, et face aux processus actuels d'affirmation, de réappropriation et de revendication, la catégorie des aînés est devenue une icône de la culture et de la tradition $»$ (p. 25). Dans ce cadre, il ne faut pas négliger l'attitude ces jeunes face à l'école (souvent coloniale) et à la langue (la leur et celle des colonisateurs) et de toute la cohorte de préjugés qui l'accompagnent. Je citerai à titre d'exemple :

« On peut très certainement s'inquiéter des conséquences à moyen terme d'un discours hégémonique et normalisant qui présente indubitablement l'envers obligé de l'école et de la scolarisation comme étant l'ignorance, la pauvreté et le sousdéveloppement. » (p. 29)

C'est ce que nous avions montré largement pour l'attitude des Kanak de Nouvelle-Calédonie face au développement et les jugements et a priori européens en la matière (Leblic, 1993), ouvrage dans lequel nous

23. Il est paru quelques mois après le volume 33-2 d'Anthropologie et sociétés consacré au thème Citoyennetés et coordonné par Natacha Gagné et Catherine Neveu. 